\title{
Measuring trends in age at first sex and age at marriage in Manicaland, Zimbabwe
}

\author{
I Cremin, ${ }^{1}$ P Mushati, ${ }^{2}$ T Hallett, ${ }^{1}$ Z Mupambireyi, ${ }^{2}$ C Nyamukapa, ${ }^{2}$ G P Garnett, ${ }^{1}$ \\ S Gregson ${ }^{1,2}$
}

${ }^{1}$ Department of Infectious Disease Epidemiology, Imperial College London, UK;

${ }^{2}$ Biomedical Research and Training Institute, Harare, Zimbabwe

Correspondence to: Ms I Cremin, Department of Infectious Disease Epidemiology, Imperial College London, St Mary's Campus, Norfolk Place, London W2 1PG, UK; ide. cremin05@imperial.ac.uk

Accepted 19 December 2008

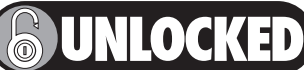

This paper is freely available online under the BMJ Journals unlocked scheme, see http:// sti.bmj.com/info/unlocked.dtl

\begin{abstract}
Objective: To identify reporting biases and to determine the influence of inconsistent reporting on observed trends in the timing of age at first sex and age at marriage.
\end{abstract}

Methods: Longitudinal data from three rounds of a population-based cohort in eastern Zimbabwe were analysed. Reports of age at first sex and age at marriage from 6837 individuals attending multiple rounds were classified according to consistency. Survival analysis was used to identify trends in the timing of first sex and marriage.

Results: In this population, women initiate sex and enter marriage at younger ages than men but spend much less time between first sex and marriage. Among those surveyed between 1998 and 2005, median ages at first sex and first marriage were 18.5 years and 21.4 years for men and 18.2 years and 18.5 years, respectively, for women aged 15-54 years. High levels of reports of both age at first sex and age at marriage among those attending multiple surveys were found to be unreliable. Excluding reports identified as unreliable from these analyses did not alter the observed trends in either age at first sex or age at marriage. Tracing birth cohorts as they aged revealed reporting biases, particularly among the youngest cohorts. Comparisons by birth cohorts, which span a period of $>40$ years, indicate that median age at first sex has remained constant over time for women but has declined gradually for men.

Conclusions: Although many reports of age at first sex and age at marriage were found to be unreliable, inclusion of such reports did not result in artificial generation or suppression of trends.

In the era of the HIV pandemic, the focus of analyses regarding timing of first sex and marriage has broadened from investigating their role as proximate determinants of fertility to encompass their associations with risk of acquiring HIV. ${ }^{1-3}$ Identifying trends in the timing of age at first sex and marriage is essential for evaluating the impact of the investment made in HIV prevention interventions to promote abstinence (by delaying first sex), and to assess the contribution of these changes to any downturn in the epidemic. ${ }^{47}$ Delays in reported age at sexual debut have coincided with declines in the prevalence of HIV in Uganda and Zimbabwe. ${ }^{8-12}$ Mathematical modelling, however, has indicated that these changes are unlikely to have contributed substantially to reductions in lifetime risk of infection or HIV incidence. $^{13}$

The relationship between age at marriage and risk of infection has received attention. Recently, Bongaarts argued that late marriage can facilitate the spread of HIV via a long period of premarital sexual activity. ${ }^{14}$ However, it is also possible for early marriage to pose an increased risk of infection if marriage leads to regular unprotected sex in serodiscordant partnerships. ${ }^{15}$

In general, the age at which first sex occurs lies within the later teenage years. ${ }^{16}{ }^{17}$ Thus, changes in the median age at first sex of just a year or two are considered epidemiologically significant. However, even modest degrees of social desirability bias, recall bias, digit preference or random misreporting could potentially generate spurious trends. For example, social desirability would be expected to bias reports of age at first sex upwards. Slaymaker and Buckner found that declines in reporting of sex before age 15 in Zambia were partially due to a change in reporting bias, when comparing two survey methodologies and accounting for the sociodemographic composition of the survey samples. ${ }^{18}$ The Manicaland cohort study in Zimbabwe, which asked individuals about the timing of first sex and marriage in three survey rounds spanning a period of 8 years, presents an opportunity to monitor trends in age at first sex and marriage as well as to gauge the consistency of reporting which may inform on the accuracy and reliability of these data.

The objectives of this paper are to (1) quantify the level of inconsistent reporting and its influence on observed trends; (2) identify reporting biases; (3) describe the overall trends in age at first sex and age at marriage; and (4) describe the length of time spent single (between first sex and marriage) in this population.

\section{METHODS \\ Study design}

The Manicaland HIV/STD Prevention Project is a population-based open cohort study in the Manicaland province of eastern Zimbabwe. The study design and procedures have been outlined in detail previously. ${ }^{12}$ Briefly, participants were recruited from 12 predominantly rural study sites which consisted of 4 subsistence farming areas, 2 small towns, 2 roadside trading areas and 4 forestry, coffee and tea estates. Local residents were enumerated initially in a household census. Eligible individuals (those present in a local household for at least four nights in the past month and at the same time one year ago) were then invited to participate in the study. This baseline survey took place in a phased manner from July 1998 to February 2000. This survey was repeated as a first follow-up from 2001 to 2003 and second follow-up from 2003 to 2005. 
Men aged 17-54 years and women aged 15-44 years were recruited with only one member of each cohabiting marital union selected at random to participate. At the second followup survey, extended entry criteria allowed men and women aged 15-54 years and both members of a marital union to participate. In the second survey (from site five onwards) and the third survey, migrants into the study areas were invited to participate.

\section{Behaviour data}

Participants were interviewed using a structured questionnaire on sociodemographic characteristics and sexual behaviour. Interviews were led by social science graduates who were familiar with the local language and culture but were not known locally. Interviewers were trained to adopt an informal and non-prejudicial approach and to build up a good rapport with respondents. Interviewers were matched for sex with respondents. An informal confidential voting interview (ICVI) method was used to collect sensitive behavioural data as a means of reducing social desirability bias. ${ }^{19}$ Participants placed slips containing their responses into a "voting" box, thus ensuring confidentiality. All data on age at first sex and age at first marriage were collected using the face-to-face interview method, even when the ICVI method was used to collect subsequent behavioural data in the same interview.

Participants were asked if they had been married or were in a long-term or cohabiting relationship, which we classify together as being "married". In the first round of the survey, relationships of $\geqslant 6$ months were defined as long-term, but in the subsequent two rounds this was changed to be relationships of $\geqslant 12$ months. Ever married individuals were asked their age when they first entered such a relationship. In the section on sexual behaviour, participants were asked initially how old they were when they had sex for the first time. Subsequent questions on sexual behaviour were asked in order of increasing sensitivity.

\section{Analysis of data}

A number of methods have been developed to analyse data on age at first sex (which also apply to age at marriage). The data used are current status (the current age of the individual and whether they have ever had sex) and recall (retrospective reports of age at first sex). ${ }^{20}$ Survival analyses combine the two sources. These techniques can also be adapted to analyse data from successive surveys to assess trends in age at first sex and distinguish underlying trends from reporting errors. ${ }^{21}$

Survival analysis techniques were employed to analyse timing of first sex, with individuals represented as surviving until first sex. In this scheme the failure event is starting sex and followup time is censored if individuals had not started sex by the time of their last interview. Censoring is independent (of the probability that sex occurs), since no information on sexual behaviour was obtained prior to recruitment. Kaplan-Meier failure curves were plotted to illustrate the cumulative onset of sexual activity. This procedure was also followed when analysing trends in age at marriage.

Age at first sex and age at marriage were reported as years in integers, which correspond to age at last birthday at those events. A random proportion of a year was added to each age to capture the distribution of exact ages within a year. Reports of age at first sex and age at marriage were classified according to consistency to assess the quality of reporting. Four categories were defined to classify reports: (1) consistent; (2) inconsistent: can be corrected; (3) inconsistent: can be estimated; and (4) unreliable: cannot be estimated or corrected (table 1).

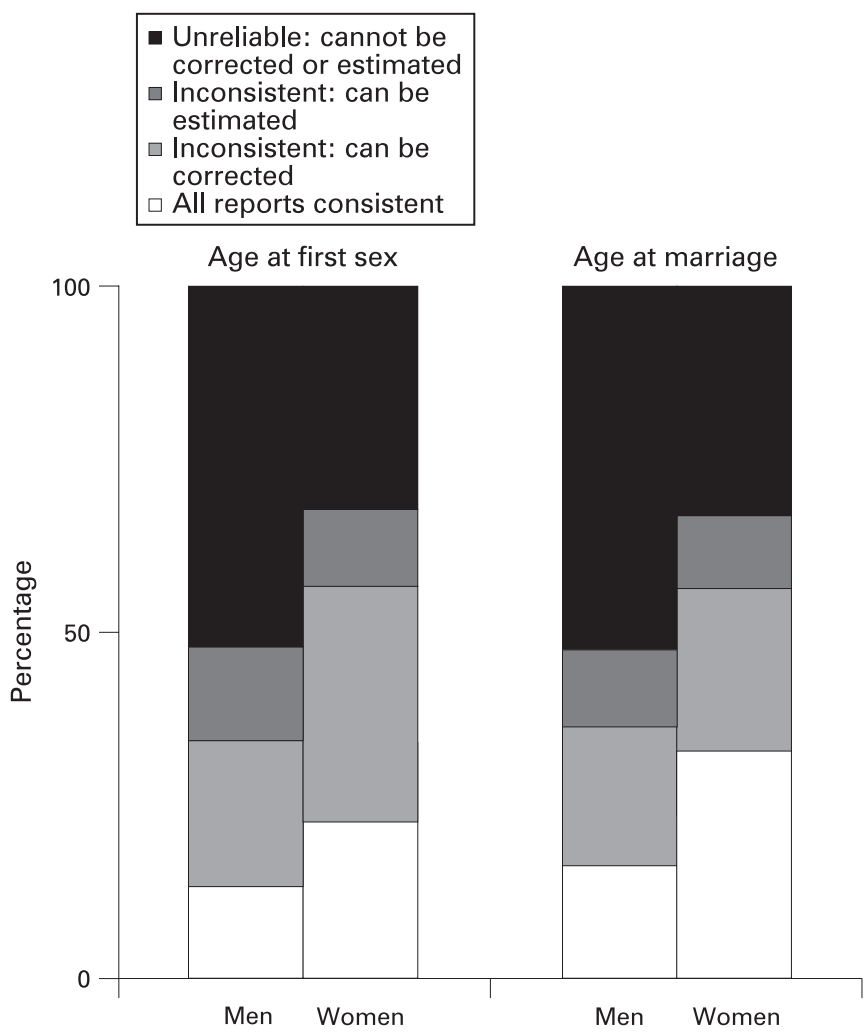

Figure 1 Consistency of reporting age at first sex and age at marriage among men and women aged $15-54$ years who reported in at least two surveys.

Table 1 Definitions of reliable and unreliable reporting

\begin{tabular}{|c|c|c|c|c|c|}
\hline \multirow[b]{2}{*}{ Category } & \multicolumn{3}{|c|}{ Number of age-at-event reports } & \multirow[b]{2}{*}{ Imputed response } & \\
\hline & 1 & 2 & 3 & & \\
\hline Consistent & Report $\leqslant$ age at survey & $\begin{array}{l}\text { Both reports same AND both } \\
\text { reports } \leqslant \text { age at survey }\end{array}$ & $\begin{array}{l}\text { All reports same AND all } \\
\text { reports } \leqslant \text { age at survey }\end{array}$ & Reported age & \multirow[t]{3}{*}{ Reliable } \\
\hline $\begin{array}{l}\text { Inconsistent: can be } \\
\text { corrected }\end{array}$ & $\mathrm{N} / \mathrm{A}$ & $\begin{array}{l}\text { Reports differ by } 1 \text { year AND } \\
\text { both reports } \leqslant \text { age at survey }\end{array}$ & $\begin{array}{l}2 \text { ages reported which differ } \\
\text { by } 1 \text { year AND both reports } \\
\leqslant \text { age at survey }\end{array}$ & Older of the 2 ages & \\
\hline $\begin{array}{l}\text { Inconsistent: can be } \\
\text { estimated }\end{array}$ & $\mathrm{N} / \mathrm{A}$ & 1 report $\leqslant$ age at survey & $\begin{array}{l}\geqslant 50 \% \text { of reports same AND } \\
\text { these reports } \leqslant \text { age at survey }\end{array}$ & $\begin{array}{l}\text { Most frequent report that is } \\
\leqslant \text { age at survey }\end{array}$ & \\
\hline $\begin{array}{l}\text { Unreliable: cannot be } \\
\text { estimated or corrected }\end{array}$ & Report $>$ age at survey & $\begin{array}{l}\text { Reports differ by }>1 \text { year } \\
\text { AND both reports } \leqslant \text { age at } \\
\text { survey OR both reports }>\text { age } \\
\text { at survey }\end{array}$ & $\begin{array}{l}<50 \% \text { of reports same } 0 \mathrm{R} \\
\geqslant 50 \% \text { reports same AND } \\
\text { reports }>\text { age at survey }\end{array}$ & Mean of all reported ages & Unreliable \\
\hline
\end{tabular}


Table 2 Median and IQR for age at first sex and age at marriage by reliability of data and birth cohort for men and women

\begin{tabular}{|c|c|c|c|c|}
\hline \multirow[b]{3}{*}{ Birth cohort } & \multicolumn{2}{|l|}{ Age at first sex } & \multicolumn{2}{|c|}{ Age at first marriage } \\
\hline & All data & Reliable data & All data & Reliable data \\
\hline & Median (IOR) & Median (IOR) & Median (IOR) & Median (IOR) \\
\hline \multicolumn{5}{|l|}{ Men } \\
\hline $1950-9$ & $20.1(18.3-22.4)$ & $19.9(18.0-22.2)$ & $24.5(22.0-27.0)$ & $24.6(21.9-27.0)$ \\
\hline $1960-9$ & $19.6(17.9-21.6)$ & $19.5(17.8-21.7)$ & $24.7(22.0-27.4)$ & $25.0(22.0-27.7)$ \\
\hline $1970-9$ & $19.0(17.3-20.9)$ & $19.0(17.2-20.9)$ & $23.2(21.2-25.2)$ & $23.4(21.3-25.4)$ \\
\hline \multicolumn{5}{|l|}{ Women } \\
\hline $1950-9$ & $19.0(17.3-20.6)$ & $18.9(17.2-20.5)$ & $19.1(17.4-20.8)$ & $18.9(17.2-20.7)$ \\
\hline $1960-9$ & $18.7(17.0-20.6)$ & $18.7(17.0-20.6)$ & $18.9(17.2-20.9)$ & $18.8(17.0-20.8)$ \\
\hline $1970-9$ & $19.0(17.4-20.8)$ & $19.0(17.5-20.8)$ & $19.3(17.7-21.1)$ & $19.3(17.7-21.2)$ \\
\hline
\end{tabular}

IQR, interquartile range.

A number of non-mutually exclusive classifications were observed for those individuals with three reports (827/3270) that is, when two reports were consistent and the other report differed by 1 year. In such cases the consistently reported age was used. These criteria were also applied when classifying reports of age at marriage. A detailed description of these classifications, by frequency of reporting, is given by Wringe et al. ${ }^{22}$

All analyses were carried out using Stata Version 10 (Stata Corp, College Station, Texas, USA).

\section{RESULTS}

The numbers of participants at the first, second and third surveys were 9530, 8210 and 16266 , respectively. In total, 23517 individuals were interviewed in at least one survey, of which 16680 were interviewed in only one survey, 3185 were interviewed in two surveys and 3652 were interviewed in all three. Most individuals who were surveyed only once were new entrants at the third survey round in which the eligibility criteria for the study were expanded, as described above.

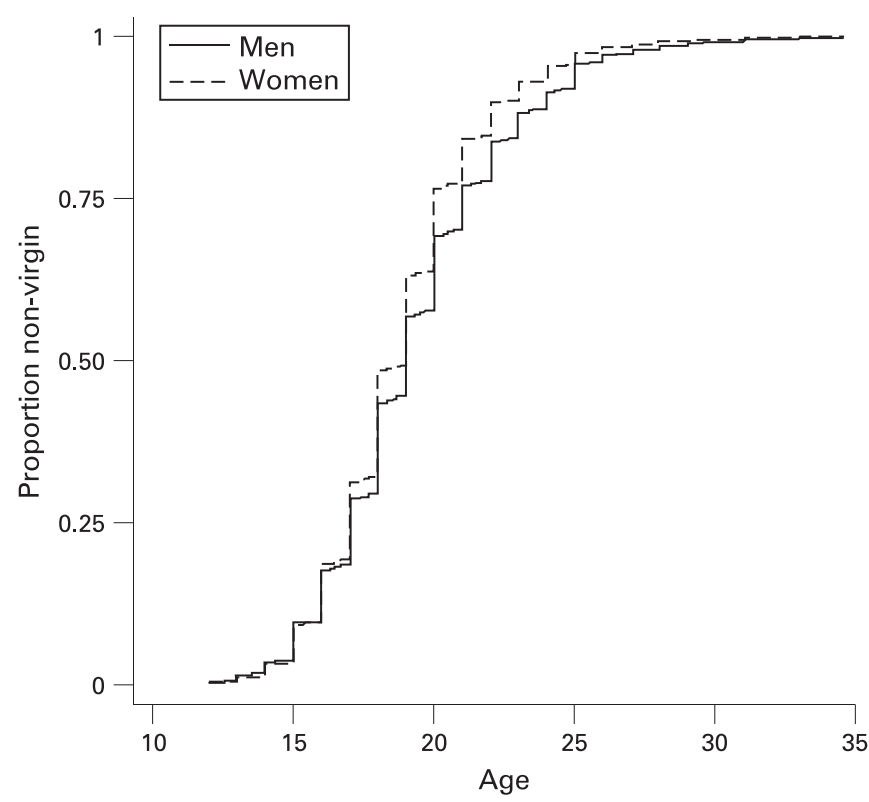

Figure 2 Kaplan-Meier failure curve for age at first sex for men and women. Data include all reports after corrections and estimations for inconsistent reports.

\section{Age at first sex}

All respondents were asked what age they were when they first had sex. Of all the surveyed individuals, 23.2\% (5446/23 517) reported never having had sex. Slightly more men than women reported never having had sex $\left(24.3 \%\right.$ vs $22.3 \%$, $\chi^{2}$ test, $\mathrm{p}<0.001)$. Of the individuals who provided a report of age at first sex, 69.3\% (12 448/17 953) only reported in one round. A small proportion of individuals did not respond to the question regarding age at first sex $(63(0.66 \%)$ in round $1,36(0.44 \%)$ in round 2 and $48(0.30 \%)$ in round 3$)$.

Reports were classed as unreliable for $32.1 \%$ of women and $52.2 \%$ of men who reported age at first sex in at least two surveys (fig 1). Of these unreliable reports, $31.2 \%, 21.2 \%$ and $15.9 \%$ of reports differed by 2,3 and 4 years, respectively. The remaining $31.6 \%$ of reports differed by $>4$ years. Similar levels of unreliable reporting were observed among only those who participated in all three surveys. The quality of reporting among those in all three surveys was very similar across birth cohorts, as described by Wringe et al. ${ }^{22}$ Excluding unreliable reports had little effect on the failure curves compared with analysing all reports (regardless of consistency) for both men and women. Median age at first sex remained largely unchanged when unreliable reports were excluded (table 2).

Age at first sex was significantly higher for men than for women (log-rank test for equality of survivorship functions: $\chi^{2}=110, p<0.001$; fig 2). Over all the surveys, $12.6 \%$ of men and $12.0 \%$ of women reported experiencing first sex at 15 years or younger.

Plotting medians by birth cohort indicated that age at first sex declined gradually among men, from 20.7 years for those born before 1955 to 19.1 years for those born after 1975 (fig 3A). For women the median age at first sex remained relatively constant between 19.2 and 19.0 years (fig 3B).

The reports from those reporting in at least two surveys were then combined and analysed in a life table format to compare reports by the same individuals as they age. The median age at first sex should remain unchanged as a cohort ages. Among those in older birth cohorts (1965-9 to before 1955), trends in age at first sex remained unchanged as these individuals aged (reading across the table), indicating the absence of reporting biases (table 3 ). However, among those in younger birth cohorts (1970-4 and after 1975), reported age at first sex increased as they aged.

\section{Age at marriage}

Across all respondents, 36.9\% (8676/23 517) reported never having been married. A higher proportion of men than women 

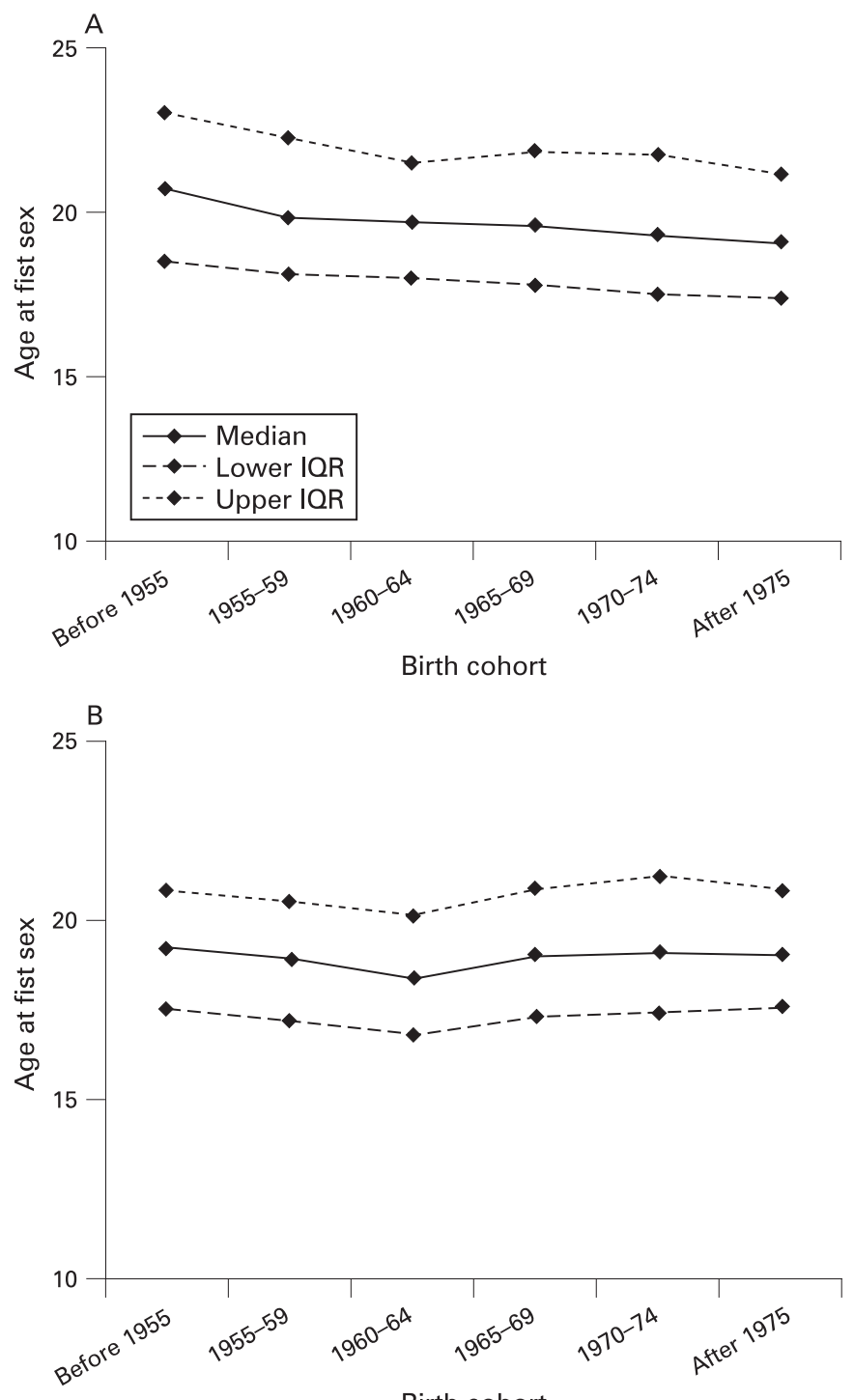

Birth cohort

Figure 3 Median estimates of reported age at first sex by 5-year birth cohort for $(A)$ men and $(B)$ women. IQR, interquartile range. Data include all reports after corrections and estimations for inconsistent reports. The upper value of the IQR could not be calculated for those born after 1975 as $60 \%$ of men and $60 \%$ of women born after 1975 reported not having had sex.

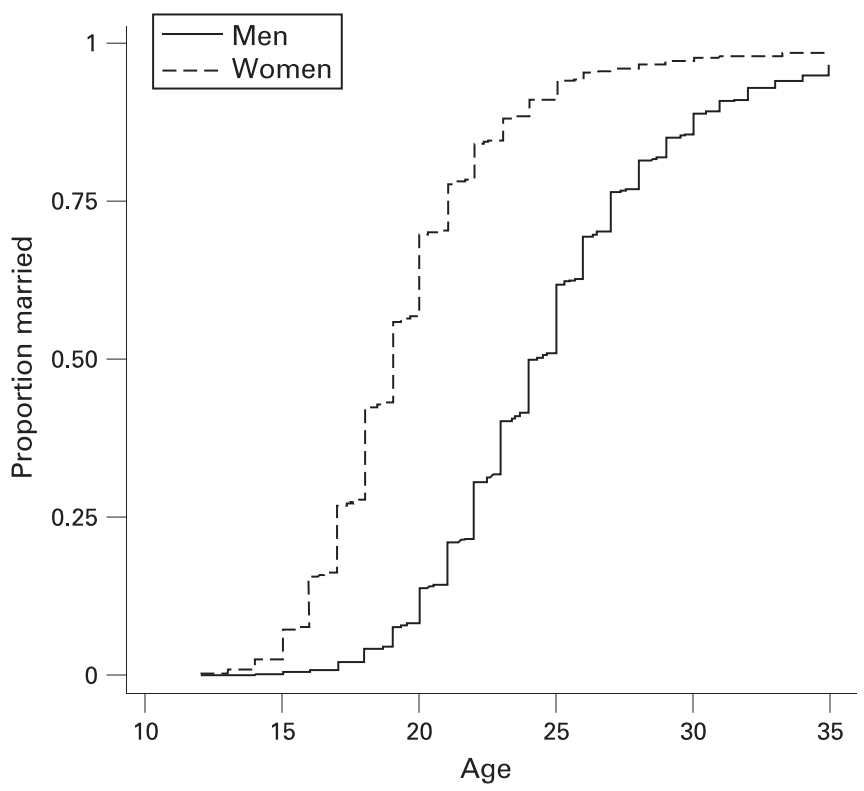

Figure 4 Kaplan-Meier failure curve for age at marriage for men and women. Data include all reports after corrections and estimations for inconsistent reports.

had never been married (50.3\% vs $26.8 \%, \chi^{2}$ test, $\mathrm{p}<0.001$ ). Participants who reported having ever been married or in a longterm relationship were asked at what age they first entered such a relationship. Of these, $43(0.72 \%), 45(0.85 \%)$ and $59(0.55 \%)$ did not respond to the question regarding age at marriage in the first, second and third surveys, respectively. Of the individuals who reported an age at marriage, 68\% (9874/14 508) only reported it in one round.

Reports were classed as unreliable for $33.2 \%$ of women and $52.5 \%$ of men who reported age at marriage in at least two surveys (fig 1). Of these unreliable reports, $26.5 \%, 17.8 \%$ and $13.7 \%$ of reports differed by 2,3 and 4 years, respectively. The remaining $41.9 \%$ of reports differed by $>4$ years. Excluding unreliable reports when plotting failure curves did not change the overall trends when compared with trends based on all reports (regardless of consistency). The median age at marriage remained largely unchanged when unreliable reports were excluded (table 2).

Table 3 Median age at first sex and number reporting (N) for men and women reporting in at least two surveys by 5-year birth cohort and age group

\begin{tabular}{|c|c|c|c|c|c|c|c|c|c|c|c|c|c|c|}
\hline \multirow[b]{2}{*}{ Birth cohort } & \multicolumn{7}{|l|}{ Men } & \multicolumn{7}{|c|}{ Women } \\
\hline & $15-19$ & $20-24$ & $25-29$ & $30-34$ & $35-39$ & $40-44$ & $45-49$ & $15-19$ & $20-24$ & $25-29$ & $30-34$ & $35-39$ & 40-44 & $45-49$ \\
\hline \multirow[t]{2}{*}{ Before 1955} & & & & & & 20.0 & 20.0 & & & & & & 19.3 & 19.0 \\
\hline & & & & & & (22) & (224) & & & & & & (42) & (436) \\
\hline \multirow[t]{2}{*}{$1955-9$} & & & & & 19.5 & 20.0 & 20.0 & & & & & 19.0 & 19.0 & 18.7 \\
\hline & & & & & (23) & (257) & (172) & & & & & (50) & (667) & (544) \\
\hline \multirow[t]{2}{*}{$1960-4$} & & & & 19.0 & 19.0 & 19.0 & & & & & 18.3 & 18.0 & 18.0 & \\
\hline & & & & (48) & (379) & (239) & & & & & (65) & (816) & (671) & \\
\hline $1965-9$ & & & (45) & (352) & (231) & & & & & (69) & (656) & (496) & & \\
\hline \multirow[t]{2}{*}{$1970-4$} & & 18.8 & 19.0 & 19.0 & & & & & 18.0 & 18.3 & 18.3 & & & \\
\hline & & (68) & (609) & (388) & & & & & (62) & (750) & (599) & & & \\
\hline \multirow[t]{2}{*}{ After 1975} & 17.0 & 18.0 & 18.3 & & & & & 17.0 & 18.0 & 18.6 & & & & \\
\hline & (415) & (1047) & (458) & & & & & (448) & (1103) & (586) & & & & \\
\hline
\end{tabular}

Data include all reports after corrections and estimations for inconsistent reports have been made. Small sample sizes are indicated in italic, along the leftmost diagonal for men and for women. These are low due to the timing of the surveys in relation to birth cohorts (eg, the majority of individuals in the 1970-4 birth cohort had aged past the 20-24 age group when they were surveyed). 

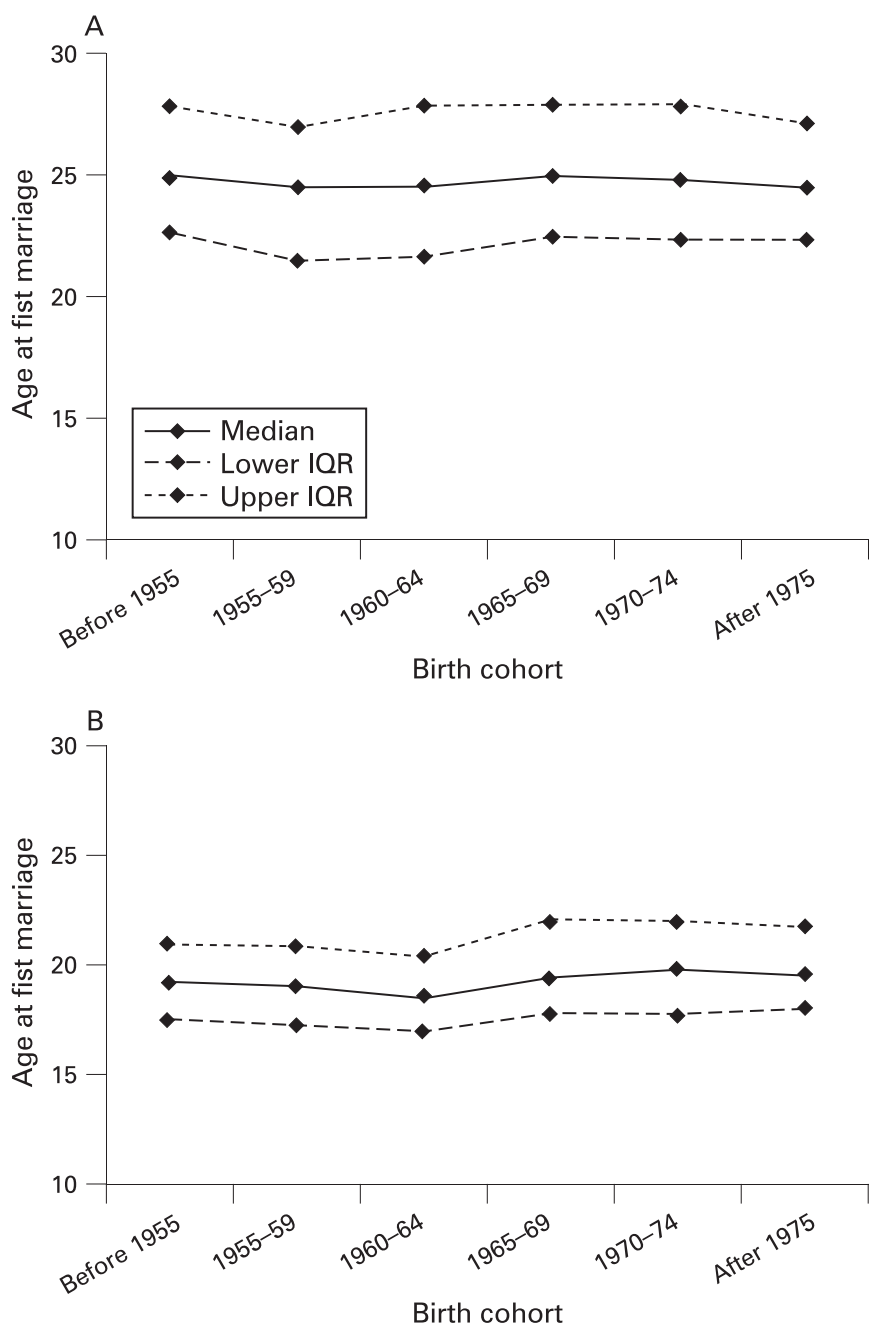

Figure 5 Median estimates of reported age at marriage by 5 -year birth cohort for (A) men and (B) women. IQR, interquartile range. Data include all reports after corrections and estimations for inconsistent reports. The IQR and median age at marriage could not be calculated for men born after 1975 as only $20 \%$ of men in this birth cohort are (or had been) married. The upper value of the IQR could not be calculated for women born after 1975 as $52 \%$ of women in this birth cohort are (or had been) married.

Men marry at significantly older ages than women (log-rank test $\chi^{2}=5647, \mathrm{p}<0.001$; fig 4 ). A stable age at marriage among men and women is also illustrated by plotting the median age for each birth cohort (fig 5).

The reports from those reporting in at least two surveys were then combined and analysed in a life table format. Men generally reported an increased age at marriage as they aged, particularly those in the youngest birth cohort (reading across the table; table 4). Women in older birth cohorts (1955-9 and before 1955) reported decreasing ages at marriage as they aged. However, for women in younger birth cohorts (1965-9 to after 1975), the reported age at marriage increased as they aged.

\section{Time spent single after sexual debut}

The average number of person-years spent between first sex and marriage has remained constant for men and women (fig 6). The mean (SD) duration of time spent single after sexual debut is much longer for men than for women (4.1 (4.1) years vs 0.3 (1.6) years). A greater proportion of women than men indicated

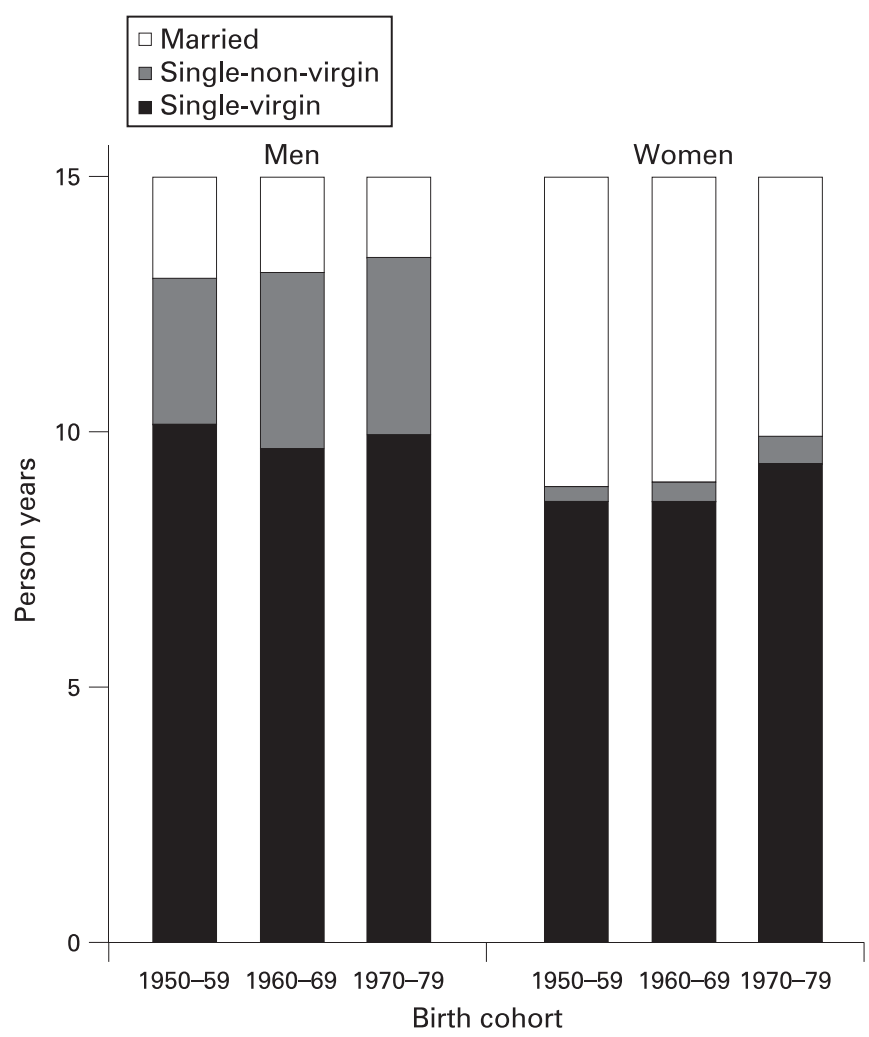

Figure 6 Distribution of person-years spent as a virgin, sexually active and unmarried and married between the ages of 10 and 25 years for men and women.

that their first sexual experience was within marriage; $69.8 \%$ (6748/9666) and $15.3 \%$ (729/4760) of married women and men, respectively, reported age at first sex to coincide with age at marriage.

\section{DISCUSSION}

Including reports of age at first sex and age at marriage identified as unreliable in survival analyses did not alter our results, suggesting that much of the unreliability may be attributable to random misreporting rather than systematic biases such as social desirability bias. This absence of alteration of trends indicates that the observed trends can be interpreted with some confidence, despite the high levels of misreporting. Furthermore, this provides some reassurance when interpreting trends in serial cross-sectional data, such as from Demographic and Health Surveys (DHS) where such inconsistencies cannot be identified. However, consistency of reporting does not always signify accuracy; an individual may consistently report an incorrect age at first sex, a bias which cannot be detected.

In this rural Zimbabwean population, women initiate sex and enter marriage at younger ages than men but spend much less time between first sex and marriage. Comparisons across all surveys by birth cohorts which span a period of $>40$ years indicate that the median age at first sex has remained constant over time among women but has declined gradually among men. Median age at marriage has remained relatively stable for both men and women. However, tracing birth cohorts between surveys revealed reporting biases. It is possible that some individuals (particularly young people) deliberately report an older age at first sex due to exposure to HIV prevention campaigns promoting delaying age at first sex and abstinence, in addition to the pressure of other social norms. With respect to 
Table 4 Median age at marriage and number reporting (N) for men and women reporting in at least two surveys by 5 -year birth cohort and age group

\begin{tabular}{|c|c|c|c|c|c|c|c|c|c|c|c|c|c|c|}
\hline \multirow[b]{2}{*}{ Birth cohort } & \multicolumn{7}{|l|}{ Men } & \multicolumn{7}{|c|}{ Women } \\
\hline & $15-19$ & $20-24$ & $25-29$ & $30-34$ & $35-39$ & $40-44$ & $45-49$ & $15-19$ & $20-24$ & $25-29$ & 30-34 & $35-39$ & 40-44 & $45-49$ \\
\hline \multirow[t]{2}{*}{ Before 1955} & & & & & & 23.8 & 24.0 & & & & & & 19.0 & 18.7 \\
\hline & & & & & & (22) & (219) & & & & & & (41) & (425) \\
\hline \multirow[t]{2}{*}{$1955-9$} & & & & & 21.0 & 23.0 & 23.0 & & & & & 19.0 & 18.0 & 18.0 \\
\hline & & & & & (22) & (254) & (168) & & & & & (49) & (661) & (541) \\
\hline \multirow[t]{2}{*}{$1960-4$} & & & & 23.5 & 23.0 & 23.0 & & & & & 18.0 & 18.0 & 18.0 & \\
\hline & & & & (45) & (364) & (234) & & & & & (63) & (803) & (664) & \\
\hline $1965-9$ & & & (42) & (324) & (216) & & & & & (67) & (645) & (492) & & \\
\hline \multirow[t]{2}{*}{$1970-4$} & & 22.6 & 23.0 & 23.0 & & & & & 18.0 & 19.0 & 18.7 & & & \\
\hline & & (50) & (441) & (307) & & & & & (59) & (710) & (573) & & & \\
\hline \multirow[t]{2}{*}{ After 1975} & 19.5 & 21.0 & 22.0 & & & & & 17.0 & 18.0 & 18.3 & & & & \\
\hline & (55) & (313) & (244) & & & & & (357) & (963) & (542) & & & & \\
\hline
\end{tabular}

Data include all reports after corrections and estimations for inconsistent reports. Small sample sizes are indicated in italic, along the leftmost diagonal for men and for women. These are low due to the timing of the surveys in relation to birth cohorts (eg, the majority of individuals in the 1970-4 birth cohort had aged past the 20-24 age group when they were surveyed).

reported age at first sex, one may expect decreasing social desirability bias and increasing recall bias as an individual ages. Such effects may generate the similar levels of unreliable reporting observed across all birth cohorts.

We previously reported delays in sexual debut among teenage men and women in the first 3 years of follow-up. ${ }^{12}$ In this earlier analysis we compared trends in the percentage of individuals reporting having had sex within a small population subgroup who were starting sex at that time (17-19-year-old men and 1517-year-old women). These age restrictions were chosen to analyse an entirely new group of maturing adolescents at each survey, thus focusing on very recent trends. These previous findings, using current status data only, are therefore not directly comparable to the longer-term trends in median age at first sex in the entire population presented here by birth cohorts spanning a period of $>40$ years.

In Zimbabwe, information on timing of sexual debut has been collected in four DHS surveys since 1988, and median age at first sex has been calculated by province for the most recent three surveys. ${ }^{23-26}$ In Manicaland, median ages among women aged 25-49 years are relatively constant at 18.3, 18.2 and 18.4 years in 1994, 1999 and 2005-6, respectively. Among men aged 25-54 years (25-49 years in the 2005-6 survey) the median age at first sex increased from 19.5 years in 1994 to 22.0 years in 1999 and subsequently decreased to 20.6 years in 2005-6. Thus, the medians calculated for women in this study population are a good representation of those in the wider population in the Manicaland province whereas, for men, the medians calculated for this study population are generally younger. Our estimates of median age at first sex are relatively high in comparison with other African countries such as Kenya, Tanzania, Uganda and Zambia where median age at first sex ranges from 16.4 to 18.1 years. $^{21}$

The substantial gender differential in age at marriage observed here is not surprising as women are expected to marry younger than men in Shona society. ${ }^{27}$ Women may seek to marry at a relatively young age in order to obtain the security associated with marriage and subsequent motherhood. Men are expected to obtain employment in order to afford bridewealth, thus re-enforcing the expectation that they wait until reaching their mid 20s before marrying. Recall bias may influence quality of reporting of age at marriage, particularly among older individuals. In this society, marriage is a long process and individuals may be unable to distinguish their age when the actual ceremony took place from that when bridewealth was paid, from when the relationship begun. The biases identified in reporting of age at marriage may also be partially attributable to the change in the definition of a long-term relationship.

A mathematical modelling study parameterised for this population has shown that the effect of delaying age at first sex on subsequent risk of HIV infection depends on the length of time spent single (between first sex and marriage). ${ }^{13}$ When sexually active and unmarried, the risk of infection is double that when married ( $2 \%$ and $1 \%$ per person-year at risk, respectively). ${ }^{13}$ Thus, the extended duration of time spent sexually active and single among men, and the brief duration of time spent sexually active and single among women observed here, support previous findings in this population that, in general, young men acquire HIV from premarital relations (as well as extramarital relations) whereas, for women (who typically spend much less time single), the strongest determinants of infection are their spouse's behaviours. ${ }^{28} 29$

Previous cross-sectional analyses (using the first round of data) investigating age at first sex in relation to subsequent risk of HIV infection found that, among both men and women in this population, riskier sexual behaviour was observed among those reporting an early age at first sex (younger than 18 years) than in those who reported an older age of sexual debut. ${ }^{3}$ However, for men, an early age at first sex which coincided with age at marriage did not lead to subsequent riskier behaviour compared with men who initiated sex at an older age. This suggests that, among men, early marriage may be somewhat protective against the riskier effects of early age at first sex.

\section{Take-home messages}

- High levels of reports of age at first sex and age at marriage were identified as unreliable among men and women attending multiple surveys.

- Excluding unreliable reports did not alter the observed trends in age at first sex and age at marriage.

- Comparing birth cohorts over a 40-year time span, median age at first sex has remained constant over time among women but has declined gradually among men.

- Median age at marriage has remained relatively stable for both men and women. 
However, the change in age at first sex observed here among men may not translate into an additional risk of infection because the average number of years spent single (between first sex and marriage) has remained the same. Thus, the circumstances in which first sex occurs may be more important than the timing.

Acknowledgements: The authors thank Emma Slaymaker for preparing the original analyses presented at a workshop held in Zimbabwe, organised by the ALPHA network.

Funding: The Wellcome Trust and the Joint United Nations Programme on HIV/AIDS supported the Manicaland HIV/STD Prevention Project. IC received PhD funding from the Division of Epidemiology, Public Health \& Primary Care, Imperial College London.

Competing interests: None.

Ethics approval: Written informed consent was given by every participant at each survey. Ethical approval for the study was granted by the Medical Research Council of Zimbabwe (number 02187) and St Mary's, London local research ethics committee (03.66 R\&D 03/SB/004E).

Contributors: SG and GPG designed the research, PM, ZM and CN performed the research, IC and TH analysed the data. All authors contributed to preparing the manuscript.

\section{REFERENCES}

1. Bongaarts J. A framework for analyzing the proximate determinants of fertility. Popul Dev Rev 1978;4:105-32.

2. Pettifor $\mathbf{A E}$, van der Straten A, Dunbar MS, et al. Early age of first sex: a risk factor for HIV infection among women in Zimbabwe. AIDS 2004;18:1435-42.

3. Hallett TB, Lewis JJ, Lopman BA, et al. Age at first sex and HIV infection in rural Zimbabwe. Stud Fam Plann 2007;38:1-10.

4. United Nations General Assembly Special Session on HIV/AIDS. Declaration of Commitment on HIV/AIDS. June 2001. http://data.unaids.org/publications/irc-pub03/ aidsdeclaration en.pdf (accessed 22 Jan 2009).

5. US Agency for International Development (USAID). What happened in Uganda? Declining HIV prevalence, behavior change, and the national response. Washington, DC: USAID, 2002.

6. Office of the United States Global AIDS Coordinator. The President's Emergency Plan for AIDS Relief. US five-year global HIVIAIDS strategy. Washington, DC: US Department of State, 2004.

7. Shelton JD, Halperin DT, Wilson D. Has global HIV incidence peaked? Lancet 2006;367:1120-2.

8. Asiimwe-Okiror G, Opio AA, Musinguzi J, et al. Change in sexual behaviour and decline in HIV infection among young pregnant women in urban Uganda. AIDS 1997;11:1757-63.
9. Stoneburner RL, Low-Beer D. Population-level HIV declines and behavioral risk avoidance in Uganda. Science 2004;304:714-8.

10. Kirungi WL, Musinguzi J, Madraa E, et al. Trends in antenatal HIV prevalence in urban Uganda associated with uptake of preventive sexual behaviour. Sex Transm Infect 2006;82(Suppl 1):i36-41.

11. Slutkin G, Okware $S$, Naamara W, et al. How Uganda reversed its HIV epidemic. AIDS Behav 2006;10:351-60.

12. Gregson S, Garnett GP, Nyamukapa CA, et al. HIV decline associated with behavior change in eastern Zimbabwe. Science 2006;311:664-6.

13. Hallett TB, Gregson S, Lewis JJ, et al. Behaviour change in generalised HIV epidemics: impact of reducing cross-generational sex and delaying age at sexual debut. Sex Transm Infect 2007;83(Suppl 1):i50-4.

14. Bongaarts J. Late marriage and the HIV epidemic in sub-Saharan Africa. Popul Stud (Camb) 2007;61:73-83.

15. Clark S. Early marriage and HIV risks in sub-Saharan Africa. Stud Fam Plann 2004;35:149-60.

16. Wellings $\mathbf{K}$, Collumbien $\mathbf{M}$, Slaymaker $\mathbf{E}$, et al. Sexual behaviour in context: a global perspective. Lancet 2006;368:1706-28.

17. Gupta N, Mahy M. Sexual initiation among adolescent girls and boys: trends and differentials in sub-Saharan Africa. Arch Sex Behav 2003;32:41-53.

18. Slaymaker E, Buckner B. Monitoring trends in sexual behaviour in Zambia, 19962003. Sex Transm Infect 2004;80(Suppl 2):iï5-90.

19. Gregson S, Mushati P, White PJ, et al. Informal confidential voting interview methods and temporal changes in reported sexual risk behaviour for HIV transmission in sub-Saharan Africa. Sex Transm Infect 2004;80(Suppl 2):ï36-42.

20. Slaymaker E. A critique of international indicators of sexual risk behaviour. Sex Transm Infect 2004;80(Suppl 2):ii13-21.

21. Zaba B, Pisani E, Slaymaker E, et al. Age at first sex: understanding recent trends in African demographic surveys. Sex Transm Infect 2004;80(Suppl 2):ii28-35.

22. Wringe A, Cremin I, Herbst $K$, et al. Comparative assessment of the quality of ageat-event reporting in three HIV cohort studies in sub-Saharan Africa. Sex Transm Infect 2009;00(Suppl X):00-0.

23. Central Statistical Office Harare (Zimbabwe), Macro International. Zimbabwe demographic and health survey 2005-6. Maryland, USA: Calverton, 2007.

24. Central Statistical Office Harare (Zimbabwe), Macro International. Zimbabwe demographic and health survey 1999. Maryland, USA: Calverton, 2000.

25. Central Statistical Office Harare (Zimbabwe), Macro International. Zimbabwe demographic and health survey 1994. Maryland, USA: Calverton, 1995.

26. Central Statistical Office Harare (Zimbabwe), Ministry of Finance Economic Planning and Development (Zimbabwe), Macro International. Zimbabwe demographic and health survey 1988. Maryland, USA: Columbia, 1989.

27. Bourdillon MFC. Where are the ancestors? Changing culture in Zimbabwe. Harare: University of Zimbabwe, 1993.

28. Gregson S, Nyamukapa CA, Garnett GP, et al. Sexual mixing patterns and sexdifferentials in teenage exposure to HIV infection in rural Zimbabwe. Lancet 2002;359:1896-903.

29. Spark-du-Prez N, Żaba B, Nyamukapa CA, et al. Kusvika taparadzaniswa nerufu (Until death do us part). Afr J AIDS Res 2004;3:81-91. 